\title{
Disability: use of an independent living fund in south east London and users' views about the system of cash versus care provision
}

\author{
Yvonne Doyle
}

\begin{abstract}
Study objectives - To describe the uses of the Independent Living Fund (ILF) in south east London and to highlight users' views about the system of cash versus care provision for people with disabilities.

Design - Face to face interviews between users of the fund and an interviewer to discuss cash for care, using a structured questionnaire.

Setting - Interviews took place in the person's home.

Participants - The database at the ILF headquarters in Nottingham of all recipients of the fund was used. People were entered into the study on an "opt-in" basis. Results - Ninety five people were interviewed, of whom $72(76 \%)$ had a modified Barthel score of less than 10. Before the ILF award, 31 (32\%) people had received no community services, although it seems that social services were targeted at those living alone among the remaining 64 people. After the award, 23 of the 64 (36\%) had their community services reduced or withdrawn. Sixty eight $(71 \%)$ people bought a total care package with their award. Forty two people (44\%) used agency care and a quarter of these had complaints about the quality of care. Seventy four (78\%) overall, and $93 \%$ of those from ethnic minorities, would opt for a system of cash for care again.

Conclusions - People used the ILF successfully to procure care of a type and flexibility which suited them and enabled them to live independently. Central government should reconsider wider cash for care schemes and the possibility of having both the statutory and non-statutory sectors on contract to some care users.
\end{abstract}

(f Epidemiol Community Health 1995;49:43-47)

Independent living has been endorsed for people with disabilities at official level in this country within the NHS and Community Care Act of 1990. ${ }^{1}$ However, it is acknowledged that people with disabilities and their carers in the UK have substantial unmet need and lack of support. ${ }^{2-5}$ This has led regularly to calls for direct cash payments to people. ${ }^{6-9}$ The arguments against cash payments are that more centrally purchased services are cheaper and will lead to economies of scale, that cash may be easily diverted from a vulnerable claimant in their home, and that groups such as ethnic minorities may not take up their entitlements. The counter arguments in favour of cash are that people are placed in control and the money is symbolic of this control. Given the choice, a substantial number of people would opt for cash. ${ }^{9}$

The Independent Living Fund (ILF) was established by the UK Government in 1988 as an independent trust. The ILF was intended to supplement care packages for independent living provided by local authorities (who are responsible for social care provision), the $\mathrm{Na}-$ tional Health Service (NHS) and, where relevant, the voluntary sector. The fund was administered from Nottingham, and employed 150 visiting social workers who conducted a standard appraisal of the applicant. If successful, the applicant received cash directly into their bank account or that of their carer.

The target group for the ILF was those severely disabled people who needed help with domestic and personal care in their home. An applicant living with a partner could buy in personal care that the partner was unable to provide. Although there were income criteria for eligibility, ${ }^{10}$ these allowed for exceptional payments to prevent people entering institutional care.

The fund was established for a maximum of five years, pending the implementation of the Community Care $A c t^{1}$ which would pass responsibility for assessment of needs and care provision for vulnerable groups to social services departments of local authorities.

Although the initial budget was $£ 15 \mathrm{~m}$, by 1993 around 22000 people nationally were in receipt of the fund and the budget had risen to $£ 97 \mathrm{~m}$. ${ }^{10}$ Because of the popularity of the fund, two new trusts have been established. One, with a budget of $£ 117 \mathrm{~m}$, provides for continued payments to the 22000 people in receipt of the ILF. The second, with an initial budget of $£ 4 \mathrm{~m}$, rising to $£ 17 \mathrm{~m}$ by $1995-96$ is for new awards to around 1500 severely disabled people of working age every year.

Previous work in south east London on the needs of young disabled people suggested that conditions were better for those in receipt of the ILF than those dependent on statutory services. ${ }^{11}$ The aim of this study was to bring the views of local users of the ILF into focus so that the relative merits or drawbacks of the system can be highlighted at a time when the future of cash or care is under debate.

Lambeth, Southwark and Lewisham Health Commission covers an inner city area with a 
population of 690000 people, of whom 1200 aged 16-64 years would have a moderate or severe physical disability. The area has a multiethnic, multi-cultural profile with areas of considerable social deprivation.

\section{Methods}

The ILF at Nottingham was approached and agreed to allow access to its database of all recipients of the fund in the Lambeth, Southwark and Lewisham Health Commission area. At the time of the study there were 198 people in receipt of the fund locally. Permission was granted to approach this entire population of users on condition that only those who initially agreed to be interviewed could be approached.

Of the 198 people located on the database, $54(27 \%)$ did not agree to enter the study; and a further $49(25 \%)$ had either died or migrated. Many of those who refused an interview were unavailable because of illness. Ninety five people were accessible and were interviewed. People were contacted personally to be interviewed in their home. Carers were invited to be present.

A structured questionnaire was prepared with reference to previous work at the ILF, ${ }^{12}$ and was piloted locally. The questionnaire sought baseline information about interviewees; services received from the statutory sector before and after the ILF award; the experience of the recipient on a wide range of practical issues around the management of their award; their concepts of independent living; and their views on the future of the fund. Disability was measured by a modified Barthel score $^{13}$ which is graded 0 (most severe) to 20 (least severe disability).

Face to face interviews with a trained field worker lasted about 40 minutes. Interviews were taped and data were transferred to a hard copy afterwards. The analysis was performed using the SPSS package.

\begin{tabular}{lrr} 
Table 1 Profile of interviewees & & \\
\hline Characteristics of interviewees & No & $(\%)$ \\
\hline Age (y): & & \\
Under 21 & 10 & $(10 \cdot 5)$ \\
$21-64$ & 63 & $(66 \cdot 3)$ \\
65-74 & 14 & $(14 \cdot 7)$ \\
Over 75 & 8 & $(8 \cdot 5)$ \\
Total & 95 & $(100 \cdot 0)$ \\
& & \\
Current or past education: & 76 & $(80 \cdot 0)$ \\
Full- or part-time mainstream & 11 & $(11 \cdot 5)$ \\
Special education & 7 & $(7 \cdot 4)$ \\
None & 1 & $(1 \cdot 1)$ \\
Missing data & 95 & $(100 \cdot 0)$ \\
Total & & \\
& & \\
Place of residence before the ILF award: & 60 & $(62 \cdot 0)$ \\
At home with someone & 27 & $(28 \cdot 0)$ \\
At home, alone & 4 & $(5 \cdot 0)$ \\
In residential accommodation & 4 & $(5 \cdot 0)$ \\
In hospital & 95 & $(100 \cdot 0)$ \\
Total & & \\
Place of residence after the ILF award: & 65 & $(68 \cdot 0)$ \\
At home with someone & 30 & $(32 \cdot 0)$ \\
At home, alone & 95 & $(100 \cdot 0)$ \\
Total & & \\
\hline
\end{tabular}

\section{Results}

Ninety five people were interviewed 50 (53\%) of whom were male and $45(47 \%)$ female. Sixty six $(69 \%)$ described themselves as white British; 28 (29\%) were from ethnic minorities of whom $9(32 \%)$ were black Caribbean; 7 (25\%) were southern European; 5 (18\%) were Indian or Asian; 3 (11\%) were black African; and $4(14 \%)$ were from other ethnic minorities. One person declined to answer this question. Table 1 outlines other characteristics of the interviewees.

Table 2 shows the medical diagnoses of interviewees. Most had congenital or acquired conditions of the nervous system. Seventy two $(76 \%)$ had a modified Barthel score of less than 10 indicating moderate or severe degrees of disability on the Barthel scale.

One third of the interviewees (31 people) had received no regular community care before their ILF award. The remaining 64 people who had received some services mainly had access to home help (72\%) and nursing care $(44 \%)$. Although $80 \%$ of those receiving a community service did not think that they got services when they most needed them, there seems to have been an attempt by social services departments offering home help to give priority to people living alone. Sixty per cent of those living alone and $45 \%$ of those living with someone received some home help. Furthermore, $44 \%$ of those living alone got more than five hours' help per week compared with only $14 \%$ of those who were not living alone.

By contrast, NHS services were less well targeted. Eighty per cent of those receiving nursing care got less than five hours of nursing care per week before the ILF award whether they lived alone or not. After the award, 17 people still wanted more nursing care, but only five people wanted more home help care.

The ILF was set up to supplement care provided by health authorities and local government. After their ILF award, 28 (44\%) of the 64 people who had access to community care experienced changes in these services. Five people had a small increase (less than two hours per week) in either home help or nursing, but $23(36 \%)$ had their services reduced or withdrawn.

Table 2 Underlying impairment of interviewees

\begin{tabular}{|c|c|c|}
\hline Impairment & No & $(\%)$ \\
\hline $\begin{array}{l}\text { Neurological, including: } \\
\text { Multiple sclerosis } \\
\text { Cerebrovascular accident } \\
\text { Cerebral palsy/spina bifida } \\
\text { Alzheimer's disease } \\
\text { Parkinson's disease } \\
\text { Others }\end{array}$ & 58 & $(61 \cdot 0)$ \\
\hline $\begin{array}{l}\text { HIV/AIDS } \\
\text { Injuries } \\
\text { Arthritis } \\
\text { Mixed learning and physical disability or } \\
\text { learning disability alone }\end{array}$ & $\begin{array}{l}8 \\
7 \\
4 \\
3\end{array}$ & $\begin{array}{l}(8 \cdot 4) \\
(7 \cdot 4) \\
(4 \cdot 2) \\
(3 \cdot 2)\end{array}$ \\
\hline $\begin{array}{l}\text { Other, including: } \\
\text { Muscular dystrophy } \\
\text { Cancer } \\
\text { Sickle cell disease } \\
\text { Polycystic disease of the kidneys } \\
\text { Systemic lupus erythematosus } \\
\text { Sjogren's syndrome } \\
\text { Missing diagnoses }\end{array}$ & 11 & $(11 \cdot 6)$ \\
\hline
\end{tabular}


Table 3 Grants received from the Independent Living Fund (ILF) and range of hours of care purchased

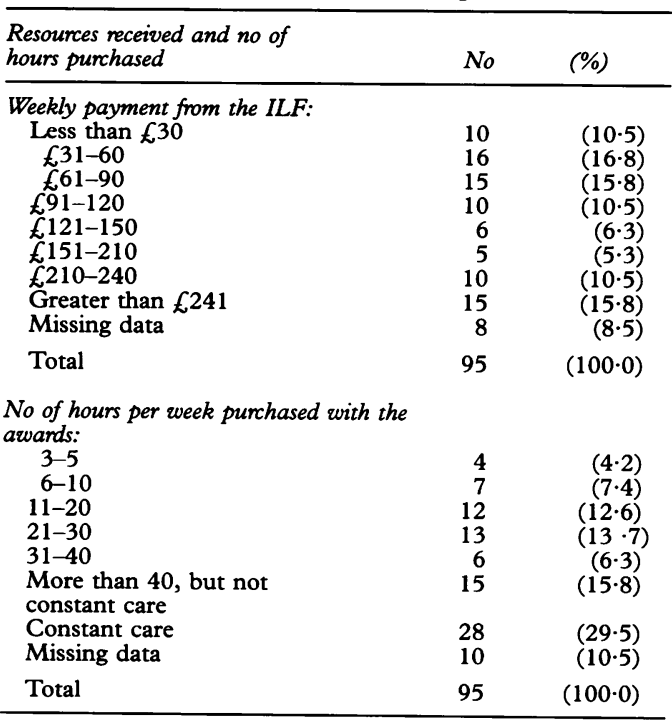

The assessment for the ILF was considered by $94(99 \%)$ to be thorough but fair. People were frequently offered more help than they had accepted. Table 3 shows the level of grant received by people and the number of hours of care purchased in each week with the grants. Sixty eight $(71.5 \%)$ people bought a total care package which covered assistance with all aspects of daily living for the hours available with the grant. The other 27 bought individual services such as domestic help, laundry, or nursing care. Sixty six (69\%) people had employed usually two concurrent carers to provide their total care packages.

Ninety one (96\%) people either dealt with the cash and employment themselves or received help from a relative - usually a child or spouse. Three of the remaining four were helped by a local housing association. Five patterns emerged in response to the role of employer: (a) $50(52.6 \%)$ people had found it difficult but had acclimatised, including 24 (83\%) of the 28 people from ethnic minorities; (b) $14(14.7 \%)$ people saw their carers as friends and not employees; (c) $9(9.5 \%)$ still did not like the employer role; (d) $5(5 \cdot 3 \%)$ people had acted as employers and did not find it strange; and (e) $17(17.9 \%)$ currently devolved their employer role to an agency. However, all felt that the administration involved was a burden, and many isolated users would have welcomed advocacy schemes for users similar to those instigated in other areas of south London. ${ }^{6}$

Seventy $(74 \%)$ people had employed several consecutive sets of assistants, although usually not more than three sets. The most consistent method of recruiting was via word of mouth, particularly a neighbour/friend (used in $26 \%$ of cases). People from ethnic minorities used a similar method and this method was also considered effective.

Forty two (44\%) interviewees were past or current users of agency care. The commonest service purchased was a total care package, provided by "auxiliary nurses". People collectively had used 23 different agencies. Twenty two $(52 \cdot 3 \%)$ people felt that the quality of care was good. Eleven (26\%) had adverse comments. A common complaint was about no quality control over staff, with a lack of predictability about who would turn up. This was considered important as the initial training of care assistants by interviewees was time consuming, and became more so with constant new arrivals from the agency. Both users and non-users of agency care commented about high charges for this care.

The advantages and drawbacks of the ILF as seen by various subgroups were examined. The groups of interest were those with a Barthel score of less than $10(76 \%)$ and those living alone $(32 \%)$, as these are vulnerable subgroups. Table 4 indicates responses concerning a range of effects of the ILF on disabled living. There were few differences in the pattern of responses between those with more and less severe disabilities, and those living alone and with someone. The exception was that those with severe disabilities found relatively more disadvantages overall with the system and particularly in relation to anxiety in finding a compatible and trustworthy carer. All groups of interviewees considered that the greatest advantages of the system was increased control and choice in daily living.

Table 4 The advantages and disadvantages of the Independent Living Fund (ILF) as seen by (a) those with more severe disabilities and (b) those living alone. Comparisons between each group and the rest of the interviewees

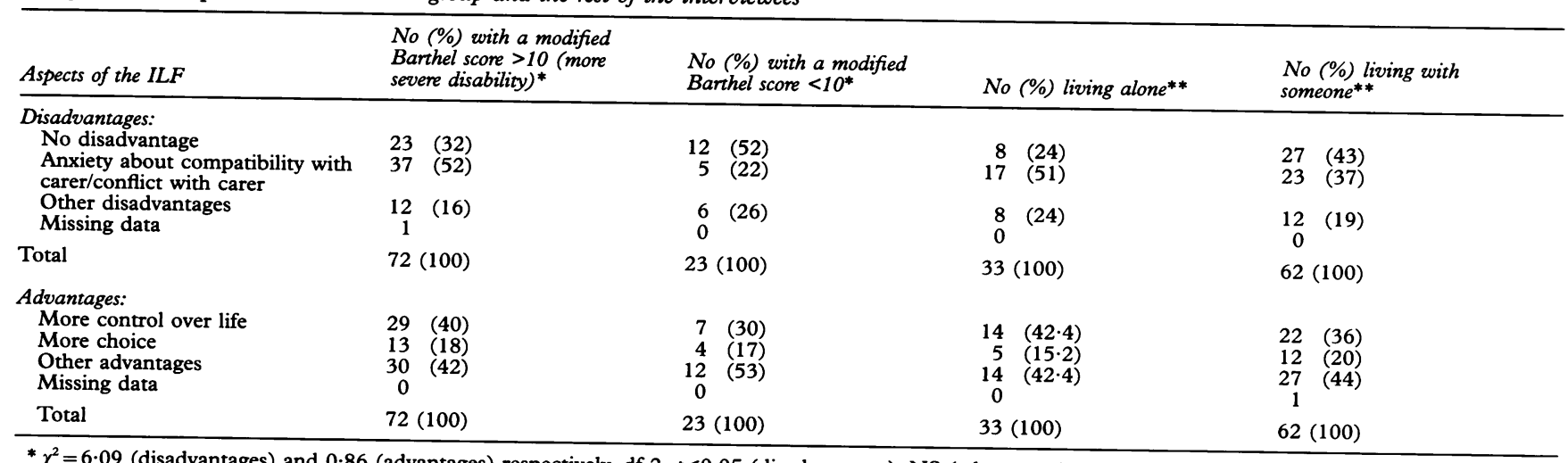

$\begin{aligned} * & \chi^{2}=6.09 \text { (disadvantages) and } 0.86 \text { (advantages) respectively. df } 2 . p<0 \cdot 05 \text { (disadvantages). NS (advantages) } \\ \chi^{2} & =3.49 \text { (disadvantages) and } 0.40 \text { (advantages) respectively. df } 2 \text {. NS (disadvantages and advantages). }\end{aligned}$ 
When asked their preferences about cash or community care provision to achieve independent living, $74(78 \%)$ people chose a system of cash payments, preferably administered by a trust such as the ILF. This group included 26 (93\%) of the 28 people from ethnic minorities. Sixteen $(17 \%)$ opted for a ring fenced fund within social services departments which would be used only for people with disabilities; three (3\%) did not mind; and two $(2 \%)$ opted for the statutory care provision they had experienced prior to their ILF award.

\section{Discussion}

In south east London, the system of offering cash to people to pay for care in the home was successful. People from a variety of backgrounds had learned to adapt the system to procure what they wanted, and had expressed satisfaction with their care arrangements.

The ILF was seen as a way of giving independence to the person and their family because money alleviated so many of the problems of poverty and dependence. ${ }^{14-15}$ Given the choice, almost $80 \%$ would opt for cash payments in future. This has been noted previously. ${ }^{9}$ Once within the ILF system, interviewees from ethnic minorities viewed the option of cash for care even more favourably than the rest of the interviewees. The current study supports previous work about the ILF in other parts of the UK. ${ }^{12}$

There is no doubt that the quantity of health and social care provision was inadequate before the ILF award, as expressed by most interviewees. However, social services departments of local government at least seem to have targeted their scarce resources towards the more vulnerable - that is, those living alone. As the ILF was mainly used by people to supplement domestic care, it is not surprising that there was less demand for home help than for nursing care after people got their cash awards. However, there was evidence of unmet need for nursing care after the ILF award.

Some people bought nursing care from agencies. There was universal agreement that agency rates were high and mixed views about the quality of the service. It is of concern that the supervision and experience of agency staff seems to be very variable. This experience ranged from fully qualified nurses with disability training through to those who did not know how to manoeuvre a wheelchair. Care users felt vulnerable in making complaints and got poor redress from the agency management. A current register of agencies should be kept by social services departments of local authorities which "grades" agencies according to cost, known quality of care, and qualifications of staff employed.

The bedrock of the recent legislation in the UK about changes in community care is that people from vulnerable groups should have a needs assessment, led by social services departments of local authorities. The legislation envisages better matching of subsequent care provision with assessed need. Recipients of the ILF have shown that they are capable of assessing their own need and arranging their own care, using designated funds. There could be real advantages in allowing a system where social services departments of local authorities functioned not just to provide care, but also to help some people to procure their own care, with designated funds. These purchaser-users of care could buy from both statutory (mainly health and social services) and non-statutory sectors (voluntary and private care). In effect, the statutory system would be on contract to service users. This would require a significant cultural shift in the statutory sector, and the logistics of these contracts would need careful planning.

In Europe, it has been noted that the quality of life for people with disabilities can be good if income and care arrangements are adequate. ${ }^{17}$ There is a flexible approach to offering cash and care in several northern European countries such as Germany, Denmark, Sweden, and The Netherlands. ${ }^{818-19}$

In The Netherlands, there is a campaign for cash payments to people for the cost of disablement. ${ }^{19}$ In the UK, the government is not in favour of a widespread system of cash payments to any care user group because it is felt that direct accountability to central administration would be lost, and rationing would be difficult. The main strength of the ILF has been to give people more control over their services and their lives. Social and health care provision for people with disabilities is frequently inflexible to the changing needs of the person. There are substantial geographical variations in the costs of statutory care which are difficult to explain. ${ }^{16}$ Central government should reconsider the option of a wider scheme of cash for care. A recently published report of the House of Commons Health Committee has encouraged the government to pursue the practicability of making cash payments to people who need help in the community. ${ }^{20}$ The ILF unearthed a large unmet need and it offered effective relief to carers who almost certainly could expect no comparable relief from local services. Informal care is worth a huge amount to the economy.

There are problems emerging already with the new ILF, where the entry criteria are more restrictive, and depend on the willingness of social services departments to match the ILF award with their own award.

Hard pressed local authorities are prevaricating so that the movement towards independent living, which received a boost from the original ILF, is now slowing down considerably. Nevertheless, the ILF is not a cheap system nationally. Although it is claimed that individual care arrangements with the fund are cost-effective in comparison to residential care provision, this is probably so because informal carers supplement care purchased with the ILF. ${ }^{16}$ Arguably, the current ILF could lead to inequity for the disabled community, diverting resources into a good service for relatively few while the rest continue to experience even poorer quantity and perhaps quality of service from health and social services.

An open debate about the future of in- 
dependent living, including the roles of the statutory and non-statutory sectors for people with disabilities would be welcome. The debate should take account of the findings from studies of the ILF, the views of the disabled community, and the economics of cash versus care provision.

I thank the 95 interviewees and their carers who gave their time and views for this report.

Anne Kestenbaum, Research Officer with the Independent Living Fund, provided helpful advice and assistance. Derek Cooper (King's College School of Medicine) provided statistical advice.

This work is supported with funding from South East Thames Regional Health Authority.

1 Secretaries of State for Health, Social Security, Wales, and Scotland. Caring for People. London: HMSO, 1989. Cmnd 849.

2 Beardshaw V. Last on the list. Community services for people with physical disabilities. London: King's Fund Institute, 1988 .

3 Edwards FC, Warren MD. Health services for adults with physical disabilities. A survey of district health authorities 1988/89. London: Royal College of Physicians, 1990.

4 Williams $\mathrm{MH}$, Bowie C. Evidence of unmet need in the care of severely physically disabled adults. BMF 1993;306: care of

5 Holland MB, Gilbertson MP. Hospital service for young adults with spina bifida and hydrocephalus. Survery in Infancy $\mathcal{E}$ Childhood 1983; Suppl 11: 113-15.

6 Oliver M, Zarb G. Greenwich personal assistant schemes. Sec- ond year evaluation - interim report. London: Oliver \& Zarb Associates/Thames Polytechnic, 1992.

7 Glendenning C. Losing ground: Social policy and disabled people in Great Britain 1980-90. Disability, Handicap and Society 1991;6:3-19.

8 Craig G. Cash or care. A question of choice? York: University of York: Social Policy Research Unit, 1993.

9 Patrick DL, Scrivens E. Allocating resources to meet needs. In: Patrick DL, Peach H eds. Disablement in the community. In: Patrick DL, Peach H eds. Disablement
Oxford: Oxford University Press, 1989.

10 Kestenbaum A. Making community care a reality. The Independent Living Fund 1988-1993. Nottingham: Independent Living Fund Living Fund, 1993

11 Doyle Y. The needs of young people with physical disabilities in the Camberwell area of south east London. London: South East London Health Authority, 1991.

12 Kestenbaum A. Cash for care. $A$ report on the experience of Independent Living Fund clients. Nottingham: Independent Living Fund, 1992

13 Wade DT, Collin C. The Barthel ADL Index. A standard measure of physical disability. Int Dis Studies 1988:10: 61-3.

14 Disability Alliance. Poverty and disability. London: Disability Alliance, 1987.

15 Hull RG, Frank A. Income and standards of living of disabled people (letter). BMF 1989;298:320.

16 Phillips V. Caring for severely disabled people. Care providers and their costs. Nottingham: Independent Living Fund, and their 1993.

17 Stensman R. Severely mobility-disabled people assess the quality of their lives. Scand F Rehab Med 1985;17:87-99.

18 Laurie G. European concepts of independent living. Rehabilitation/WORLD 1980;6:24-47.

19 Mitchell P. A comparison of social provisions for people with disabilities in the Netherlands and UK. London: Royal Association for Disability and Rehabilitation, 1983.

20 House of Commons Health Committee. Community care: 